Article

\title{
A Novel and Cost-Effective Drive Circuit for Supplying a Piezoelectric Ceramic Actuator with Power-Factor-Correction and Soft-Switching Features
}

\author{
Chun-An Cheng $\mathbb{D}^{\circ}$, Hung-Liang Cheng $\mathbb{D}^{\mathbb{B}}$, Chien-Hsuan Chang $\mathbb{D}$, En-Chih Chang *, Chih-Yang Tsai \\ and Long-Fu Lan
}

check for

updates

Citation: Cheng, C.-A.; Cheng, H.-L.; Chang, C.-H.; Chang, E.-C.; Tsai, C.-Y.; Lan, L.-F. A Novel and Cost-Effective Drive Circuit for Supplying a

Piezoelectric Ceramic Actuator with Power-Factor-Correction and Soft-Switching Features.

Micromachines 2021, 12, 1229.

https://doi.org/10.3390/mi12101229

Academic Editor: Huikai Xie

Received: 18 September 2021

Accepted: 7 October 2021

Published: 9 October 2021

Publisher's Note: MDPI stays neutral with regard to jurisdictional claims in published maps and institutional affiliations.

Copyright: (C) 2021 by the authors Licensee MDPI, Basel, Switzerland. This article is an open access article distributed under the terms and conditions of the Creative Commons Attribution (CC BY) license (https:// creativecommons.org/licenses/by/ $4.0 /)$.
Department of Electrical Engineering, I-Shou University, Kaohsiung City 84001, Taiwan; cacheng@isu.edu.tw (C.-A.C.); hlcheng@isu.edu.tw (H.-L.C.); chchang@isu.edu.tw (C.-H.C.); isu10701011m@cloud.isu.edu.tw (C.-Y.T.); isu11001004m@cloud.isu.edu.tw (L.-F.L.)

* Correspondence: enchihchang@isu.edu.tw; Tel.: +886-7-6577711 (ext. 6642)

Abstract: This paper proposes a novel and cost-effective drive circuit for supplying a piezoelectric ceramic actuator, which combines a dual boost AC-DC converter with a coupled inductor and a half-bridge resonant DC-AC inverter into a single-stage architecture with power-factor-correction (PFC) and soft-switching characteristics. The coupled inductor of the dual boost AC-DC converter sub-circuit is designed to work in discontinuous conduction mode (DCM), so the PFC function can be realized in the proposed drive circuit. The resonant tank of the half-bridge resonant inverter sub-circuit is designed as an inductive load, so that the two power switches in the presented drive circuit can achieve zero-voltage switching (ZVS) characteristics. A $50 \mathrm{~W}$-rated prototype drive circuit providing a piezoelectric ceramic actuator has been successfully implemented in this paper. From the experimental results at $110 \mathrm{~V}$ input utility-line voltage, the drive circuit has the characteristics of high power factor and low input current total-harmonic-distortion factor, and two power switches have ZVS characteristics. Therefore, satisfactory outcomes from measured results prove the function of the proposed drive circuit.

Keywords: drive circuit; power-factor-correction; zero-voltage switching; piezoelectric ceramic actuator

\section{Introduction}

Piezoelectric ceramic actuators generate vibrations with a frequency above $20 \mathrm{kHz}$ through the piezoelectric effect and have the characteristics of high accuracy, fast response, low power consumption, miniaturization, and high-density configuration. Piezoelectric ceramic actuators are widely used in low-power ultrasonic energy conversion circuits (such as ultrasonic beauty equipment, dental scalers, and atomizers) and high-power ultrasonic energy conversion circuits (such as ultrasonic cleaning machines, ultrasonic processing machines, and ultrasonic welding machines) [1-7]. Figure 1 shows a photo of a piezoelectric ceramic actuator. The equivalent circuit model of the piezoelectric ceramic actuator is shown in Figure 2, where the voltage source vOUT is the voltage output from the driving circuit to the piezoelectric ceramic actuator; the capacitance $C_{\mathrm{p}}$ is the static capacitance of the piezoelectric ceramic actuator; the resistance $R_{\mathrm{m}}$ is the mechanical equivalent resistance; $L_{\mathrm{m}}$ is the mechanical equivalent inductance, and $C_{\mathrm{m}}$ is the mechanical equivalent capacitance [8-11].

Figure 3 shows the conventional two-stage drive circuit for supplying a piezoelectric ceramic actuator applied with a DC input voltage source $V_{\text {IN-DC }}$ [12], which consists of a front-stage DC-DC boost converter (including an inductor $L_{\mathrm{b}}$, a power switch $S_{\mathrm{b}}$, a diode $D_{\mathrm{b}}$ along with a DC-linked capacitor $C_{\mathrm{b}}$ ), and a rear-stage DC-AC full-bridge resonant converter (including four power switches $S_{1}, S_{2}, S_{3}$, and $S_{4}$ and a resonant inductor $L_{\mathrm{r}}$ ) that provides rated power to the piezoelectric ceramic actuator. 


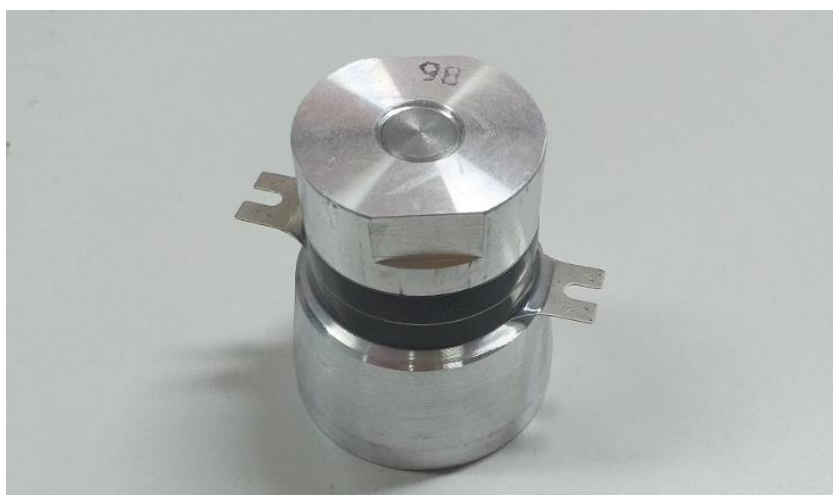

Figure 1. The photo of a piezoelectric ceramic actuator.

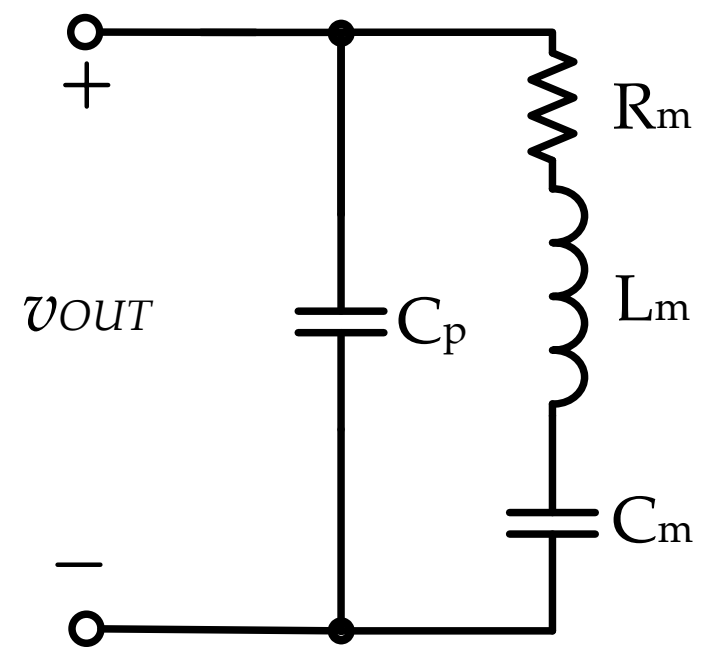

Figure 2. The equivalent circuit model for a piezoelectric ceramic actuator.

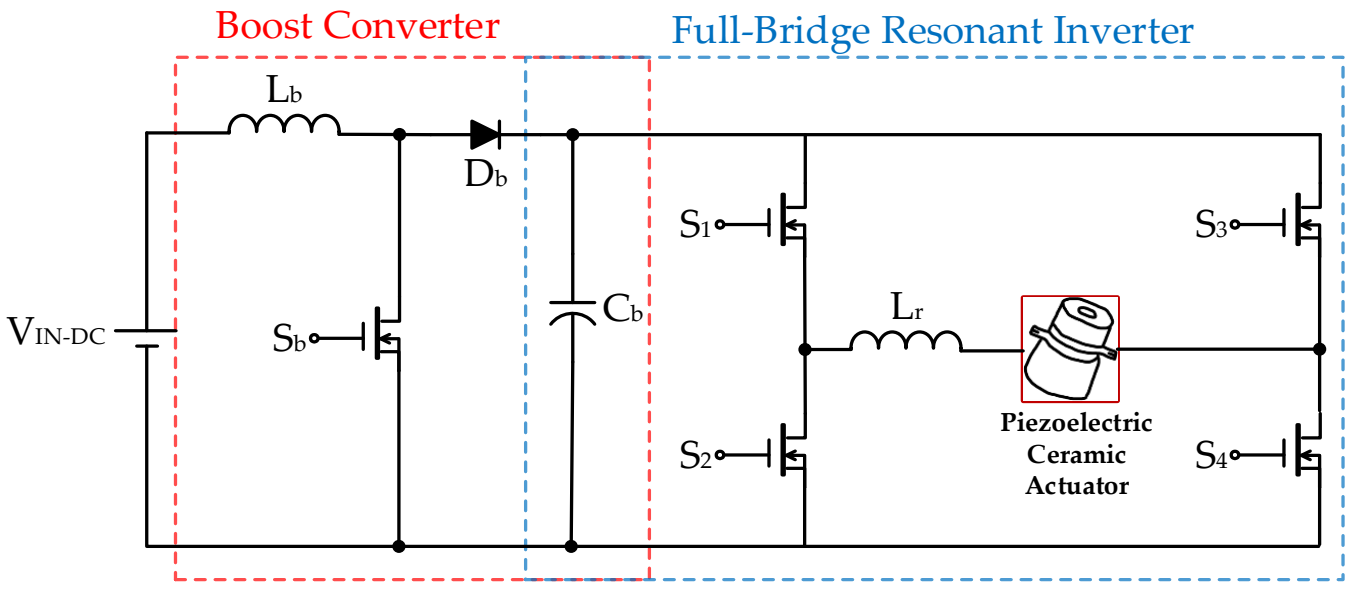

Figure 3. The conventional two-stage drive circuit for supplying a piezoelectric ceramic actuator applied with a DC input voltage source [12].

Figure 4 shows the conventional two-stage drive circuit for supplying a piezoelectric ceramic actuator applied with a AC input voltage source $v_{\mathrm{AC}}$ and without power-factorcorrection (PFC) [13,14], which consists of a front-stage AC-DC full-bridge rectifier (including four diodes $D_{\mathrm{R} 1}, D_{\mathrm{R} 2}, D_{\mathrm{R} 3}$, and $D_{\mathrm{R} 4}$ along with a DC-linked capacitor $C_{\mathrm{DC}}$ ) and a rear-stage DC-AC full-bridge resonant converter (including four power switches $S_{1}, S_{2}, S_{3}$, 
and $S_{4}$; four diodes $D_{1}, D_{2}, D_{3}$, and $D_{4}$; and a resonant inductor $L_{r}$ ) that provides rated power to the piezoelectric ceramic actuator.

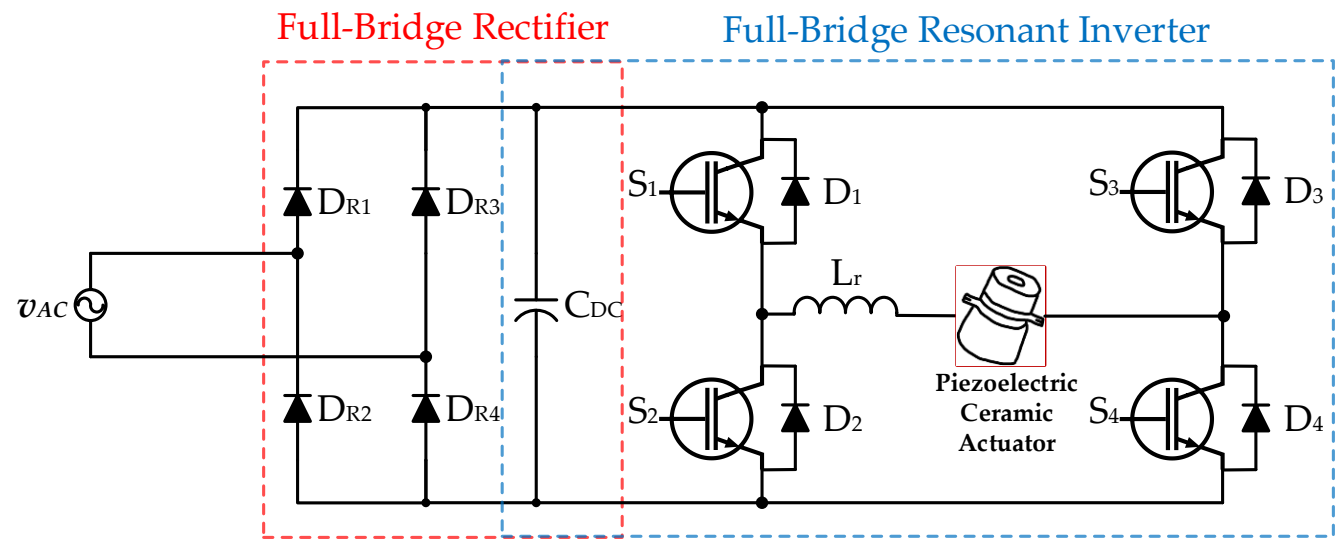

Figure 4. The conventional two-stage drive circuit for supplying a piezoelectric ceramic actuator applied with an AC input voltage source without PFC [13,14].

The traditional driving circuit that supplies power to the piezoelectric ceramic actuator requires more power switches, and the switching loss and conduction loss generated by the power switches are relatively large, which will affect the overall efficiency of the circuit. In response to these challenges, this paper presents a novel and cost-effective drive circuit for providing a piezoelectric ceramic actuator with PFC and soft-switching functions, which integrates a dual boost converter with a coupled inductor and a halfbridge resonant inverter. Descriptions of the operational modes and design equations along with experimental results of the proposed drive circuit are demonstrated in what follows.

\section{The Proposed Drive Circuit for Supplying a Piezoelectric Ceramic Actuator}

\subsection{Introduction of Proposed Drive Circuit}

Figure 5 shows the proposed drive circuit with PFC, which integrates a dual boost converter with a coupled inductor and a half-bridge resonant inverter, for supplying a piezoelectric ceramic actuator. The dual boost converter with a coupled-inductor subcircuit, which is followed by an input $A C$ voltage $v_{A C}$ and a filter $\left(L_{\mathrm{f}}\right.$ and $\left.C_{\mathrm{f}}\right)$, consists of two diodes $\left(D_{1}\right.$ and $\left.D_{2}\right)$, a coupled-inductor $\left(L_{\mathrm{B} 1}\right.$ and $\left.L_{\mathrm{B} 2}\right)$, two power switches $\left(S_{1}\right.$ and $\left.S_{2}\right)$, and two DC-linked capacitors $\left(C_{\mathrm{DC} 1}\right.$ and $\left.C_{\mathrm{DC} 2}\right)$. The half-bridge resonant inverter sub-circuit includes two switches $\left(S_{1}\right.$ and $\left.S_{2}\right)$, two DC-linked capacitors $\left(C_{\mathrm{DC} 1}\right.$ and $\left.C_{\mathrm{DC} 2}\right)$, and a resonant inductor $\left(L_{\mathrm{r}}\right)$ along with the piezoelectric ceramic actuator. In addition, the coupled-inductor $\left(L_{\mathrm{B} 1}\right.$ and $\left.L_{\mathrm{B} 2}\right)$ is designed to be operated in discontinuous-conduction mode (DCM) in order to accomplish input-current shaping. 


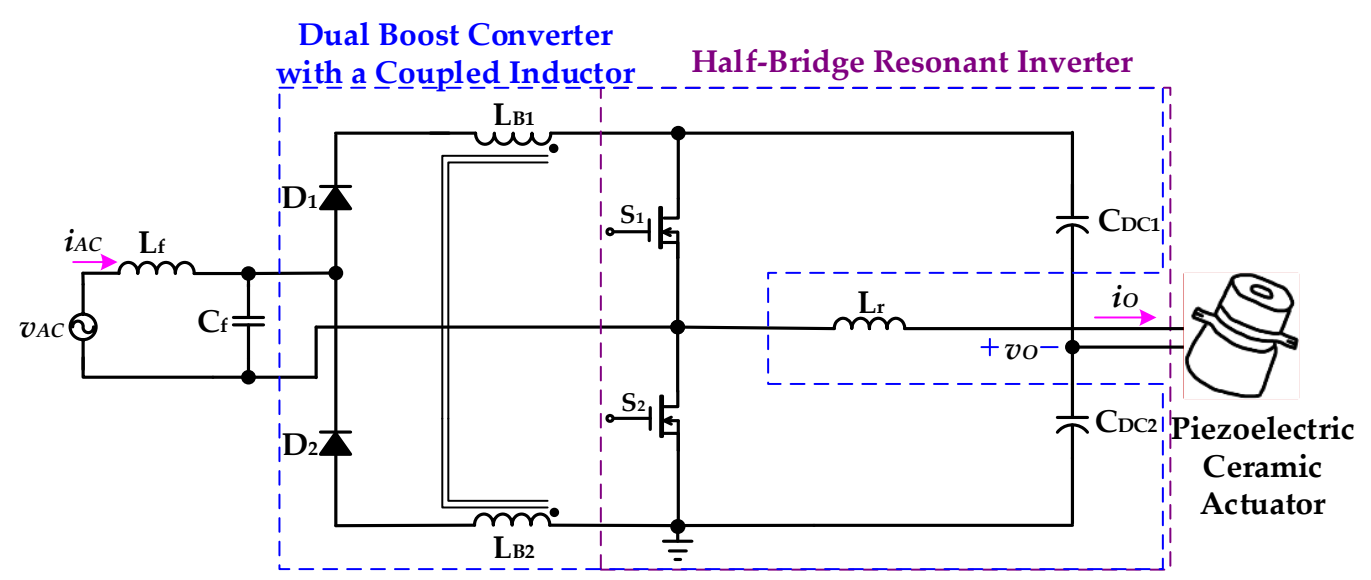

Figure 5. The proposed drive circuit for supplying a piezoelectric ceramic actuator with PFC.

Table 1 shows comparisons between the conventional two-stage drive circuits in References [12-14] and the proposed single-stage one for the piezoelectric ceramic actuator. It can be seen that the proposed drive circuit has the characteristics of power-factorcorrection and soft switching and requires fewer power switches than in References [12-14], so it can be a cost-effective alternative version for supplying a piezoelectric ceramic actuator.

Table 1. Comparisons between the conventional drive circuits and the proposed version for a piezoelectric ceramic actuator.

\begin{tabular}{|c|c|c|c|}
\hline Item & $\begin{array}{c}\text { Conventional } \\
\text { Two-Stage } \\
\text { Drive Circuit [12] }\end{array}$ & $\begin{array}{c}\text { Conventional } \\
\text { Two-Stage } \\
\text { Drive Circuit }[13,14]\end{array}$ & $\begin{array}{c}\text { Proposed } \\
\text { Single-Stage } \\
\text { Drive Circuit }\end{array}$ \\
\hline Number of Required Power Switches & 5 & 4 & 2 \\
\hline Number of Required Diodes & 1 & 8 & 2 \\
\hline Number of Required Capacitors & 1 & 1 & 3 \\
\hline Number of Required Magnetic Components & 2 & 1 & 3 \\
\hline $\begin{array}{c}\text { Input Voltage Source Suitable for } \\
\text { the Application }\end{array}$ & DC Voltage & AC Voltage & AC Voltage \\
\hline Function of Power-Factor-Correction & Not Available & No & Yes \\
\hline Soft-Switching of Power Switches & Not All Switches & $\begin{array}{c}\text { Yes } \\
\text { (All Switches) }\end{array}$ & $\begin{array}{c}\text { Yes } \\
\text { (All Switches) }\end{array}$ \\
\hline
\end{tabular}

\subsection{Analysis of Operational Modes}

When analyzing the operational modes of the piezoelectric ceramic actuator drive circuit, the assumptions made for some circuit components are as follows:

- The control signals of the power switches $S_{1}$ and $S_{2}$ are in a complementary state, and the essential diodes and parasitic capacitances on the power switches are considered.

- $\quad$ The two coupled inductors $L_{\mathrm{B} 1}$ and $L_{\mathrm{B} 2}$ in the drive circuit are designed to operate in discontinuous-conduction Mode (DCM).

- $\quad$ The equivalent resistance of diodes $D_{1}$ and $D_{2}$ and the forward bias voltage drop are ignored in the analysis.

- $\quad$ The remaining circuit components are assumed to be ideal.

The operating modes and theoretical waveforms of the proposed piezoelectric ceramic driver drive circuit during the positive half-cycle of the utility-line voltage are shown in Figures 6-12, respectively. The circuit analysis and operating modes of the drive circuit during the positive half-cycle of the utility-line voltage are described and discussed in detail below. 


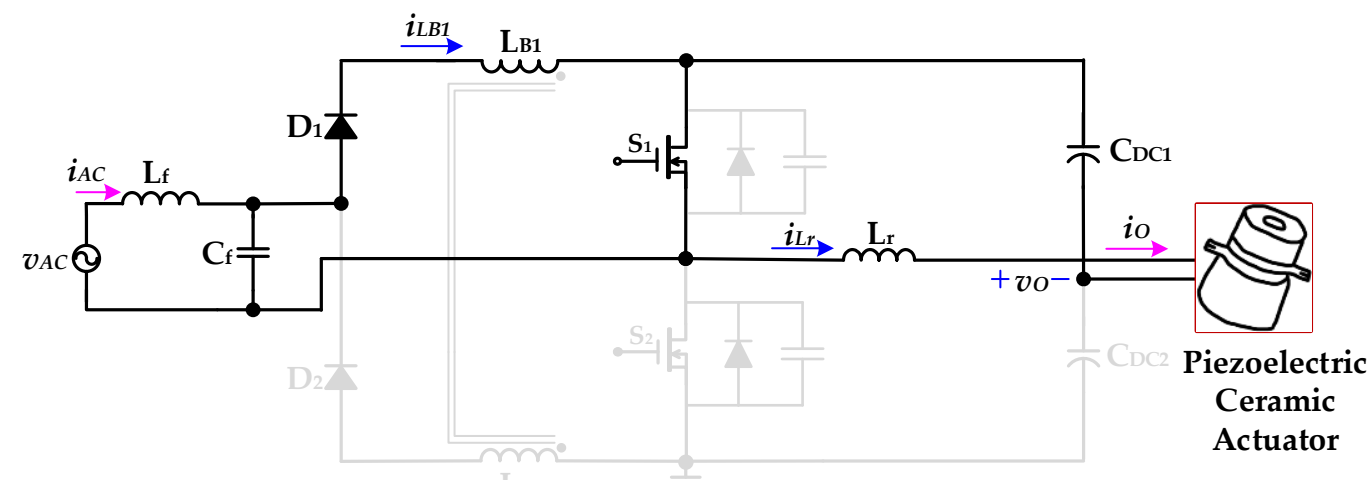

Figure 6. Operation Mode 1 of the proposed drive circuit for the piezoelectric ceramic actuator.

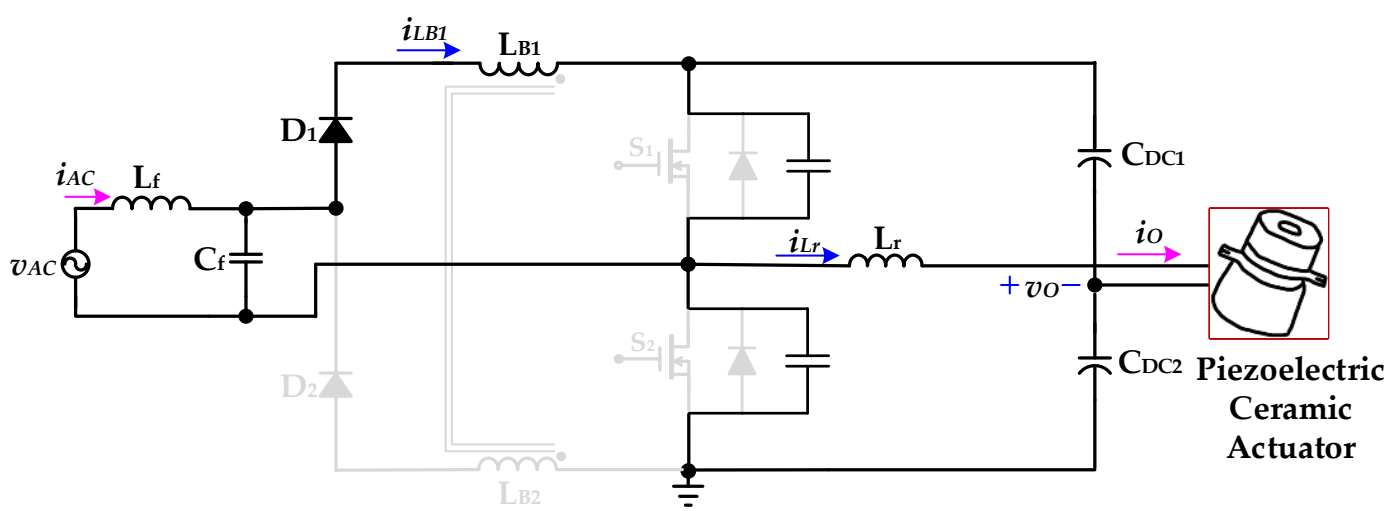

Figure 7. Operation Mode 2 of the proposed drive circuit for the piezoelectric ceramic actuator.

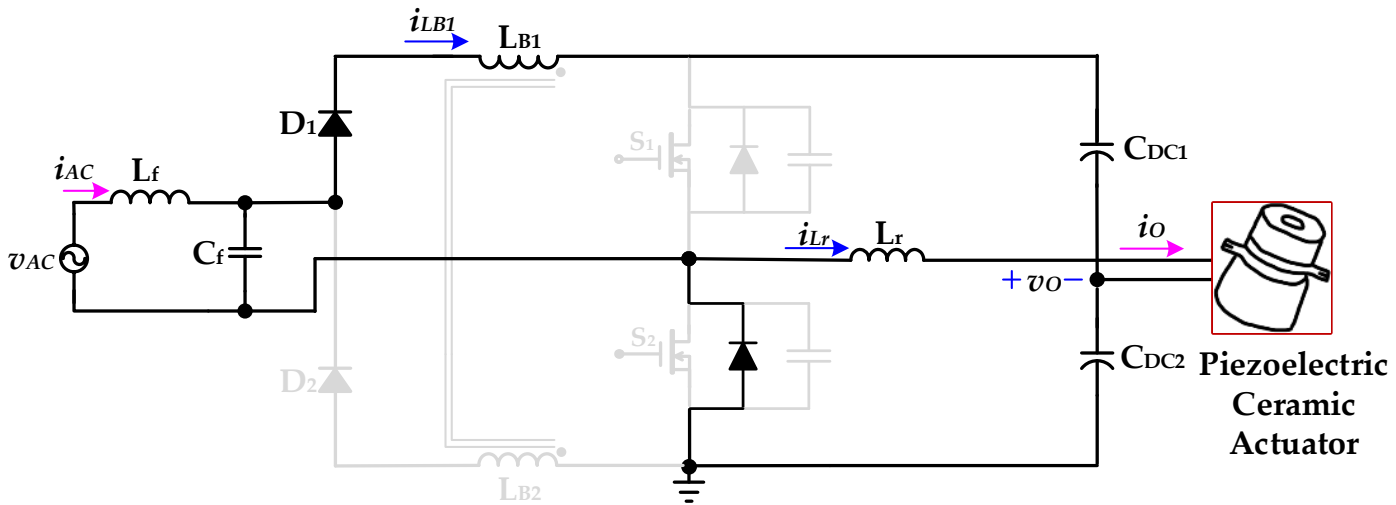

Figure 8. Operation Mode 3 of the proposed drive circuit for the piezoelectric ceramic actuator. 


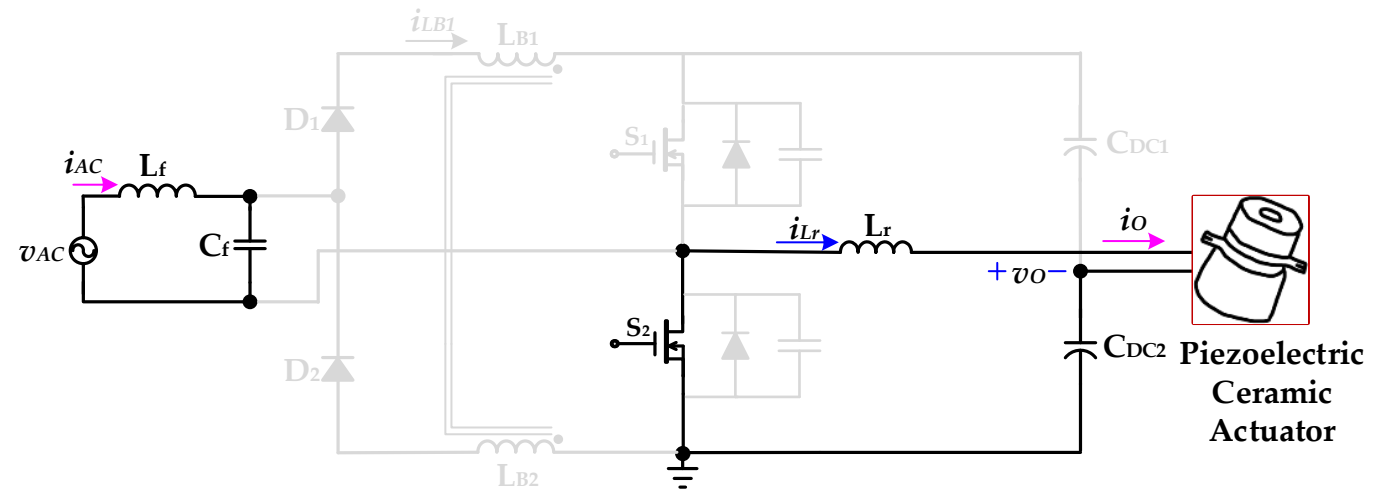

Figure 9. Operation Mode 4 of the proposed drive circuit for the piezoelectric ceramic actuator.

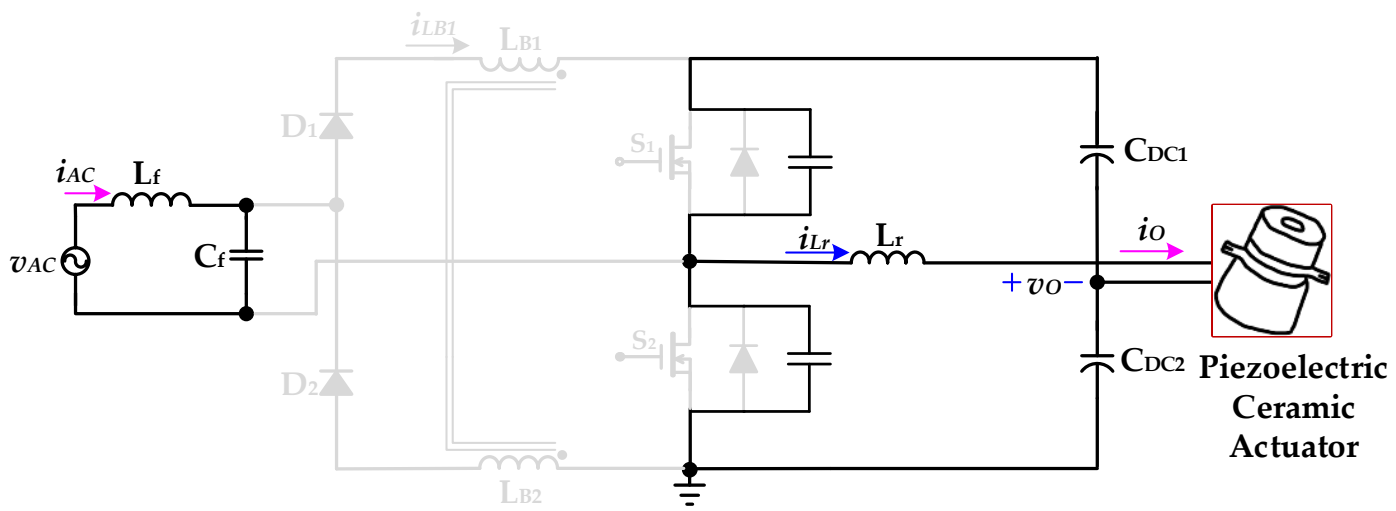

Figure 10. Operation Mode 5 of the proposed drive circuit for the piezoelectric ceramic actuator.

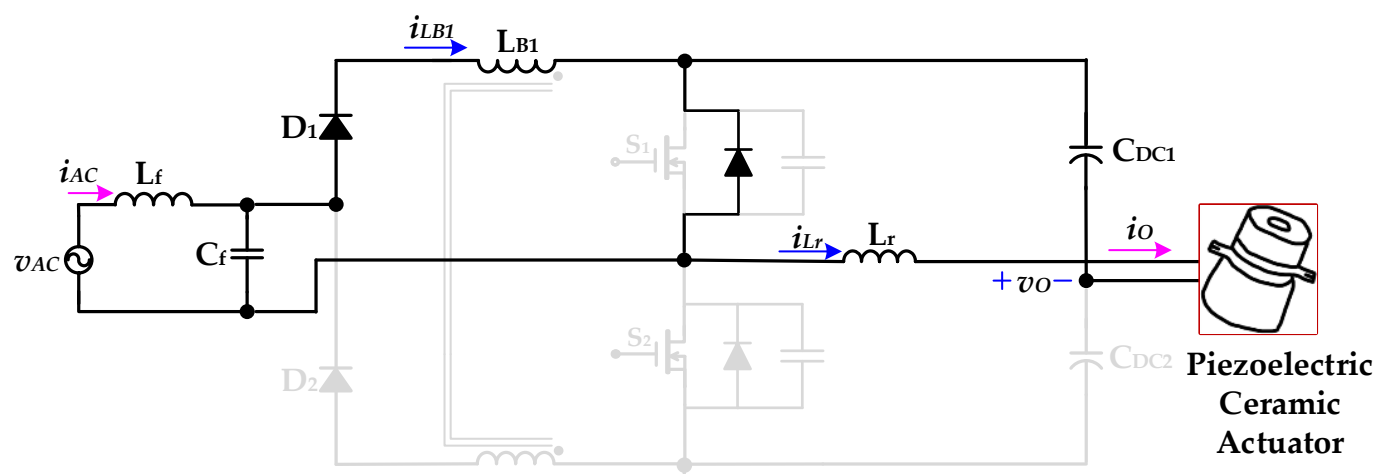

Figure 11. Operation Mode 6 of the proposed drive circuit for the piezoelectric ceramic actuator. 


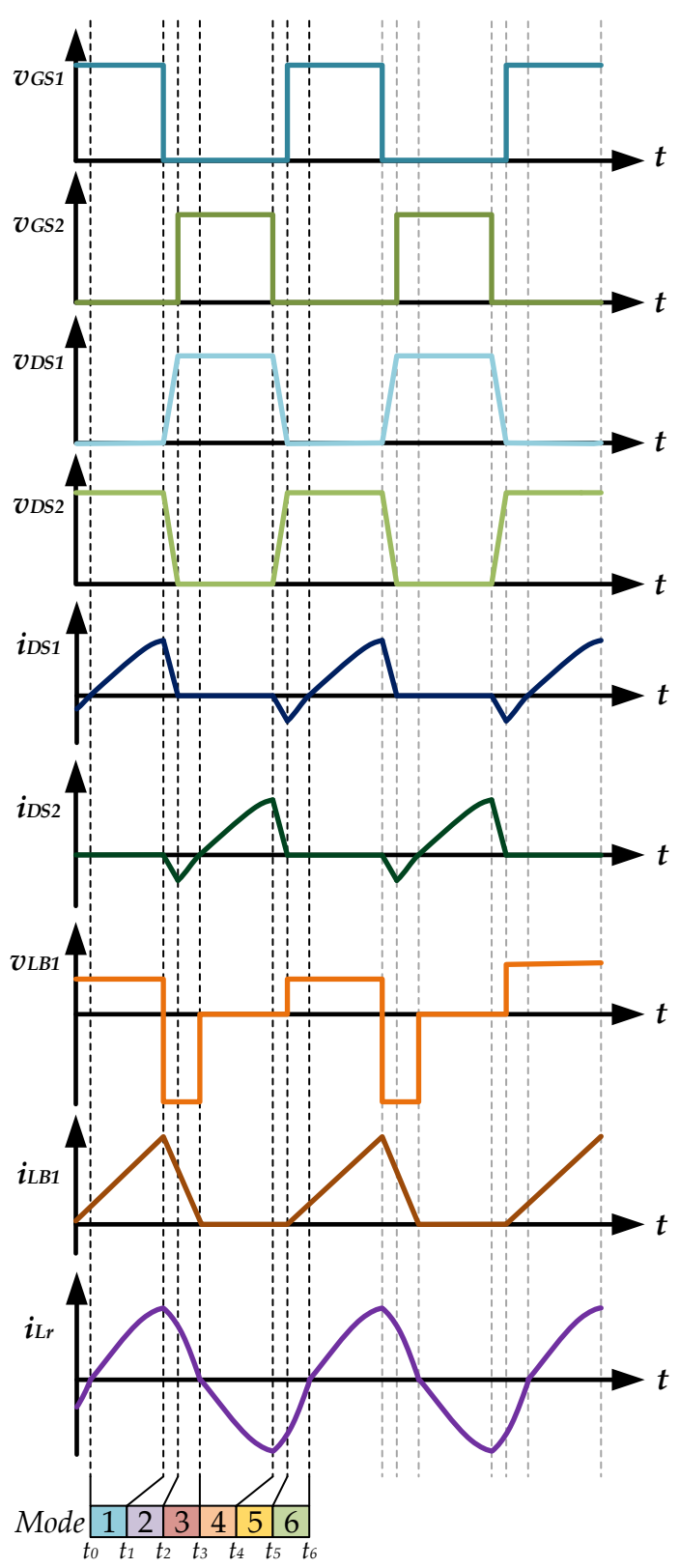

Figure 12. Theoretical waveforms of the proposed drive circuit of the piezoelectric ceramic actuator during the positive half-cycle of the utility-line voltage.

\subsubsection{Operational Mode $1\left(\mathrm{t}_{0} \leq \mathrm{t}<\mathrm{t}_{1}\right)$}

Figure 6 shows the operational Mode 1 of the new piezoelectric ceramic actuator drive circuit with PFC. In the previous operation mode, the essential diode of the power switch $S_{1}$ is forward-biased conduction. When the resonant inductor current $i_{\mathrm{Lr}}$ drops to zero, the power switch $S_{1}$ is driven on and has ZVS. The voltage source $v_{A C}$ provides energy to the coupled inductor $L_{\mathrm{B} 1}$ through the inductance $L_{\mathrm{f}}$ and the capacitor $C_{\mathrm{f}}$ of the filter circuit, the diode $D_{1}$ and the power switch $S_{1}$, and the coupled inductor current $i_{\text {LB1 }}$ presents a linear increase. The DC-linked capacitor $C_{\mathrm{DC} 1}$ charges the resonant inductor $L_{\mathrm{r}}$ through the power switch $S_{1}$ and provides energy to the piezoelectric ceramic actuator. When the power switch $S_{1}$ is turned off, the inductor current $i_{\mathrm{LB} 1}$ rises to the maximum value. At time $t_{1}$, Mode 1 ends. 


\subsubsection{Operational Mode $2\left(\mathrm{t}_{1} \leq \mathrm{t}<\mathrm{t}_{2}\right)$}

Figure 7 shows the operational Mode 2 of the new piezoelectric ceramic actuator drive circuit with PFC. The voltage source $v_{\mathrm{AC}}$ provides energy to the parasitic capacitance of the power switch $S_{1}$ through the inductance $L_{\mathrm{f}}$ and the capacitance $C_{\mathrm{f}}$ of the filter circuit, the diode $D_{1}$, and the coupling inductor $L_{\mathrm{B} 1}$, and the coupling inductor current $i_{\mathrm{LB} 1}$ begins to decrease linearly. The DC-linked capacitor $C_{\mathrm{DC}}$ and the resonant inductor $L_{\mathrm{r}}$ charge the parasitic capacitance of the power switch $S_{1}$ and provide energy to the piezoelectric ceramic actuator. The parasitic capacitance of the power switch $S_{2}$ and the resonant inductance $L_{\mathrm{r}}$ provide energy to the load and provide energy for the DC-linked capacitor $C_{\mathrm{DC} 2}$. When the parasitic capacitance of the power switch $S_{2}$ releases energy, the voltage $v_{\mathrm{DS} 2}$ of the power switch $S_{2}$ drops to zero, and the essential diode of the power switch $S_{2}$ is forwardly biased and turned on. At time $t_{2}$, Mode 2 ends.

\subsubsection{Operational Mode $3\left(\mathrm{t}_{2} \leq \mathrm{t}<\mathrm{t}_{3}\right)$}

Figure 8 shows the operational Mode 3 of the new piezoelectric ceramic actuator drive circuit with PFC. The voltage source $v_{\mathrm{AC}}$ and the coupled inductor $L_{\mathrm{B} 1}$ charge the DClinked capacitors $C_{\mathrm{DC} 1}$ and $C_{\mathrm{DC} 2}$ through the inductance $L_{\mathrm{f}}$ and capacitor $C_{\mathrm{f}}$ of the filter circuit, the diode $D_{1}$, and the essential diode of the power switch $S_{2}$. At this time, the coupled inductor current $i_{\mathrm{LB} 1}$ shows a linear decrease. The resonant inductor $L_{\mathrm{r}}$ charges the DC-linked capacitor $C_{\mathrm{DC} 2}$ through the essential diode of the power switch $S_{2}$ and provides energy to the piezoelectric ceramic actuator. When the coupled inductor current $i_{\mathrm{LB} 1}$ and the resonant inductor current $i_{\mathrm{Lr}}$ drop to zero, Mode 3 ends.

\subsubsection{Operational Mode $4\left(\mathrm{t}_{3} \leq \mathrm{t}<\mathrm{t}_{4}\right)$}

Figure 9 shows the operational Mode 4 of the new piezoelectric ceramic actuator drive circuit with PFC. When the coupled inductor current $i_{\mathrm{LB} 1}$ drops to zero, the power switch $S_{2}$ is driven to turn on and has a ZVS characteristic. The DC-linked capacitor $C_{\mathrm{DC} 2}$ charges the resonant inductor $L_{\mathrm{r}}$ through the power switch $S_{2}$ and provides energy to the piezoelectric ceramic actuator. When the power switch $S_{2}$ is turned off, Mode 4 ends.

\subsubsection{Operational Mode $5\left(\mathrm{t}_{4} \leq \mathrm{t}<\mathrm{t}_{5}\right)$}

Figure 10 shows the operational Mode 5 of the new piezoelectric ceramic actuator drive circuit with PFC. The resonant inductor $L_{r}$ and the parasitic capacitance of the power switch $S_{1}$ charge the DC-linked capacitor $C_{\mathrm{DC} 1}$ and provide energy to the piezoelectric ceramic actuator. At the same time, the resonant inductor $L_{\mathrm{r}}$ and the DC-linked capacitor $C_{\mathrm{DC} 2}$ charge the parasitic capacitance of the power switch $S_{2}$ and provide energy to the piezoelectric ceramic actuator. When the parasitic capacitance energy of the power switch $S_{1}$ is released and the voltage $v_{\text {DS1 }}$ of the power switch $S_{1}$ drops to zero, the essential diode of the power switch $S_{1}$ is forwardly biased and turned on. At time $t_{5}$, Mode 5 completes.

\subsubsection{Operational Mode $6\left(\mathrm{t}_{5} \leq \mathrm{t}<\mathrm{t}_{6}\right)$}

Figure 11 shows the operational Mode 6 of the new piezoelectric ceramic actuator drive circuit with PFC. In the previous operational mode, the energy of the parasitic capacitance of the power switch $S_{1}$ is released, the voltage $v_{\text {DS1 }}$ of the power switch $S_{1}$ drops to zero, and the essential diode of the power switch $S_{1}$ is turned on in a forward bias. The voltage source $v_{\mathrm{AC}}$ provides energy to the coupled inductor $L_{\mathrm{B} 1}$ through the inductance $L_{\mathrm{f}}$ and the capacitor $C_{\mathrm{f}}$ of the filter circuit and the diode $D_{1}$, and the coupled inductor current $i_{\mathrm{LB} 1}$ rises linearly from zero. In addition, through the essential diode of the power switch $S_{1}$, the resonant inductor $L_{\mathrm{r}}$ and the voltage source $v_{\mathrm{AC}}$ provide energy to the DC-linked capacitor $C_{\mathrm{DC} 1}$ and the piezoelectric ceramic actuator. When the resonant inductor current $i_{\text {Lr }}$ drops to zero and the power switch $S_{1}$ is driven and turned on, Mode 6 ends and the circuit operation returns to Mode 1.

In addition, Table 2 shows states of the main power devices in each operational mode during the positive half-cycle of the utility-line voltage. 
Table 2. States of the main power devices in each operational mode during the positive half-cycle of the utility-line voltage.

\begin{tabular}{|c|c|c|c|c|c|c|}
\hline $\begin{array}{c}\text { Main } \\
\text { Power Devices }\end{array}$ & Mode 1 & Mode 2 & Mode 3 & Mode 4 & Mode 5 & Mode 6 \\
\hline Switch $S_{1}$ & On & Off & Off & Off & Off & Off \\
\hline Switch $S_{2}$ & Off & Off & Off & On & Off & Off \\
\hline Diode $D_{1}$ & On & On & On & Off & Off & On \\
\hline Diode $D_{2}$ & Off & Off & Off & Off & Off & Off \\
\hline Inductor $L_{\mathrm{B} 1}$ & Charging & Discharging & Discharging & Discharging & Not Available & Charging \\
\hline Inductor $L_{\mathrm{B} 2}$ & Not Available & Not Available & Not Available & Not Available & Not Available & Not Available \\
\hline Inductor $L_{\mathrm{r}}$ & Charging & Discharging & Discharging & Discharging & Discharging & Charging \\
\hline Capacitor $C_{\mathrm{DC} 1}$ & Discharging & Discharging & Charging & Not Available & Discharging & Charging \\
\hline Capacitor $C_{\mathrm{DC} 2}$ & Not Available & Charging & Charging & Discharging & Discharging & Not Available \\
\hline
\end{tabular}

\subsection{Design Equations of Key Circuit Parameters}

2.3.1. Design Equation of the Coupled Inductors $L_{\mathrm{B} 1}$ and $L_{\mathrm{B} 2}$

The design equation of the coupled inductors $L_{\mathrm{B} 1}$ and $L_{\mathrm{B} 2}$ can be represented by [15]:

$$
L_{B 1}=\frac{\eta v_{\mathrm{AC}-\mathrm{rms}}^{2} D^{2}}{2 P_{O} f_{S}}=L_{B 2}
$$

where $\eta$ is the estimated efficiency of the proposed drive circuit; $v_{\mathrm{AC} \text {-rms }}$ is the root-meansquare (rms) value of the input utility-line voltage $v_{\mathrm{AC}} ; D$ and $f_{\mathrm{S}}$ are the duty ratio and switching frequency of the power switches, respectively; $P_{\mathrm{O}}$ is the output power. From the Formula (1), it can be drawn that Figure 13 shows the relationship between the coupled inductors $L_{\mathrm{B} 1}$ and $L_{\mathrm{B} 2}$ and the duty cycle $D$ at different switching frequencies $f_{\mathrm{S}}$.

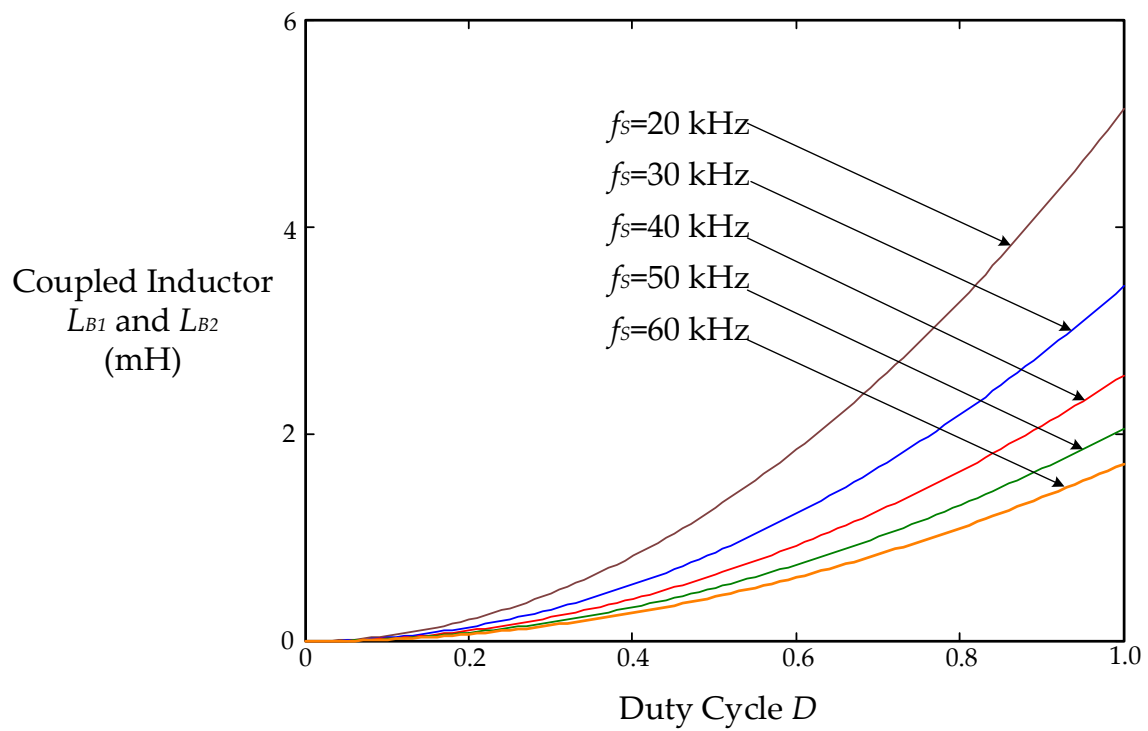

Figure 13. The relationship between the coupled inductors $L_{\mathrm{B} 1}$ and $L_{\mathrm{B} 2}$ and the duty cycle $D$ at different switching frequencies $f_{\mathrm{S}}$.

With a $\eta$ of 0.8 , a $v_{\text {AC-rms }}$ of $110 \mathrm{~V}$, a $D$ of 0.5 , a $P_{\mathrm{O}}$ of $50 \mathrm{~W}$, and a switching frequency $f_{\mathrm{S}}$ of $40 \mathrm{kHz}$, the inductances of the coupled inductors $L_{\mathrm{B} 1}$ and $L_{\mathrm{B} 2}$ are calculated as

$$
L_{B 1}=L_{B 2}=\frac{\eta v_{\mathrm{AC}-\mathrm{rms}}{ }^{2} D^{2}}{2 P_{O} f_{S}}=\frac{0.8 \cdot 110^{2} \cdot 0.5^{2}}{2 \cdot 50 \cdot 40 k}=650 \mu \mathrm{H}
$$

In addition, the coupled inductors $L_{\mathrm{B} 1}$ and $L_{\mathrm{B} 2}$ in the prototype drive circuit are $500 \mu \mathrm{H}$. 


\subsubsection{Design Equation of the Resonant Inductor $L_{\mathrm{r}}$}

Figure 14 shows the equivalent circuit diagram of the resonant inductor combined with the piezoelectric ceramic actuator circuit model; $v_{\text {inv }}$ and $i_{\text {inv }}$ respectively represent the input voltage and current of the equivalent circuit; $Z_{\mathrm{PCA}}$ represents the equivalent circuit model of the piezoelectric ceramic actuator; $Z_{\text {in }}$ represents the input impedance of the equivalent circuit. The output power $P_{\mathrm{O}}$ of the piezoelectric ceramic actuator is provided by the fundamental component of the input current $i_{\text {inv }}$ of the resonant tank circuit, and the switching frequency $f_{\mathrm{S}}$ of the power switch is designed to be equal to the resonant frequency $f_{\mathrm{r}}$ of the piezoelectric ceramic actuator. In addition, at the resonance frequency of the piezoelectric ceramic actuator, the equivalent series impedance in the right branch of the $Z_{\mathrm{PCT}}$ resonance tank circuit is reduced to only the resistance $R_{\mathrm{m}}$. The rms value $I_{\text {inv1-rms }}$ of the fundamental component of the current $i_{\text {inv }}$ can be expressed as [13]

$$
I_{\text {inv1-rms }}=\frac{R_{m}-j\left(\frac{1}{2 \pi f_{r} C_{p}}\right)}{-j\left(\frac{1}{2 \pi f_{r} C_{p}}\right)}\left(\sqrt{\frac{P_{O}}{R_{m}}}\right)
$$

The input impedance $Z_{\text {in }}$ of the equivalent circuit is expressed as

$$
Z_{\text {in }}=Z_{\mathrm{PCA}}+j Z_{\mathrm{Lr}}=\left(R_{1}+j X_{1}\right)+j 2 \pi f_{r} L_{r}
$$

where $R_{1}$ and $X_{1}$ are the equivalent resistance and reactance of the piezoelectric ceramic actuator impedance $Z_{\mathrm{PCA}}$, and they can be respectively expressed as [13]

$$
\begin{aligned}
& R_{1}=\frac{R_{m}}{1+\left(2 \pi f_{r}\right)^{2} C_{p}^{2} R_{m}^{2}} \\
& X_{1}=\frac{2 \pi f_{r} C_{p} R_{m}^{2}}{1+\left(2 \pi f_{r}\right)^{2} C_{p}^{2} R_{m}^{2}}
\end{aligned}
$$

After dividing the maximum value of the input voltage $V_{\text {inv1-max }}$ by the maximum value of the input current $\sqrt{ } 2 I_{\text {inv1-rms }}$ of the equivalent circuit, the amplitue of the input impedance $Z_{\text {in }}$ can be expressed as

$$
\left|Z_{\text {in }}\right|=\frac{V_{\text {inv1-max }}}{\sqrt{2} I_{\text {invl-rms }}}=\frac{8 V_{\mathrm{DC}}}{\sqrt{2} \pi I_{\text {invl-rms }}}
$$

where $V_{\text {inv1-max }}$ is the maximum level of the fundamental component $V_{\text {inv1 }}$ of the input voltage $v_{\text {inv }}$ of the resonant tank circuit; $V_{\mathrm{DC}}$ is the voltage level of the DC-linked capacitors $C_{\mathrm{DC} 1}$ and $C_{\mathrm{DC} 2}$.

By combining (3) with (6), the design formula of the resonant inductor $L_{\mathrm{r}}$ can be expressed as [13]

$$
L_{r}=\frac{1}{2 \pi f_{r}}\left(X_{1}+\sqrt{\left|Z_{\text {in }}\right|_{2}-R_{1}^{2}}\right)
$$

With a $R_{\mathrm{m}}$ of $25 \Omega$, a $C_{\mathrm{p}}$ of $4000 \mathrm{pF}$, a $P_{\mathrm{O}}$ of $50 \mathrm{~W}$, and a resonant frequency $f_{\mathrm{r}}$ of $40 \mathrm{kHz}$, the parameter $I_{\text {inv1-rms }}$ is calculated as

$$
I_{\text {inv1-rms }}=\frac{R_{m}-j\left(\frac{1}{2 \pi f_{r} C_{p}}\right)}{-j\left(\frac{1}{2 \pi f_{r} C_{p}}\right)}\left(\sqrt{\frac{P_{O}}{R_{m}}}\right)=\frac{25-j\left(\frac{1}{2 \pi \cdot 40 k \cdot 4000 p}\right)}{-j\left(\frac{1}{2 \pi \cdot 40 k \cdot 4000 p}\right)}\left(\sqrt{\frac{50}{25}}\right)=1.414 \angle 1.432^{0} \mathrm{~A}
$$

The parameters $R_{1}$ and $X_{1}$ are respectively calculated as

$$
R_{1}=\frac{R_{m}}{1+\left(2 \pi f_{r}\right)^{2} C_{p}^{2} R_{m}^{2}}=\frac{25}{1+(2 \pi \cdot 40 k)^{2} \cdot(4000 p)^{2} \cdot 25^{2}}=24.98 \Omega
$$




$$
X_{1}=\frac{2 \pi f_{r} C_{p} R_{m}^{2}}{1+\left(2 \pi f_{r}\right)^{2} C_{p}^{2} R_{m}^{2}}=\frac{2 \pi \cdot 40 k \cdot 4000 p \cdot 25^{2}}{1+(2 \pi \cdot 40 k)^{2} \cdot(4000 p)^{2} \cdot 25^{2}}=0.625 \Omega
$$

With a $V_{\mathrm{DC}}$ of $700 \mathrm{~V}$ and a $I_{\text {rnv1-rms }}$ of $1.414 \mathrm{~A}$, the parameter $\left|Z_{\text {in }}\right|$ is calculated as

$$
\left|Z_{\text {in }}\right|=\frac{V_{\text {inv-max }}}{\sqrt{2} I_{\text {invl-rms }}}=\frac{8 V_{\text {DC }}}{\sqrt{2} \pi I_{\text {invl-rms }}}=\frac{8 \cdot 700}{\sqrt{2} \pi \cdot 1.414}=891.4 \Omega
$$

Therefore, the parameter $L_{\mathrm{r}}$ is calculated as

$$
L_{r}=\frac{1}{2 \pi f_{r}}\left(X_{1}+\sqrt{\left|Z_{\text {in }}\right| 2-R_{1}^{2}}\right)=\frac{1}{2 \pi \cdot 40 k}\left(0.625+\sqrt{891.4^{2}-24.98^{2}}\right)=3.55 \mathrm{mH}
$$

In addition, the resonance inductor $L_{\mathrm{r}}$ in the prototype drive circuit is $3.95 \mathrm{mH}$.

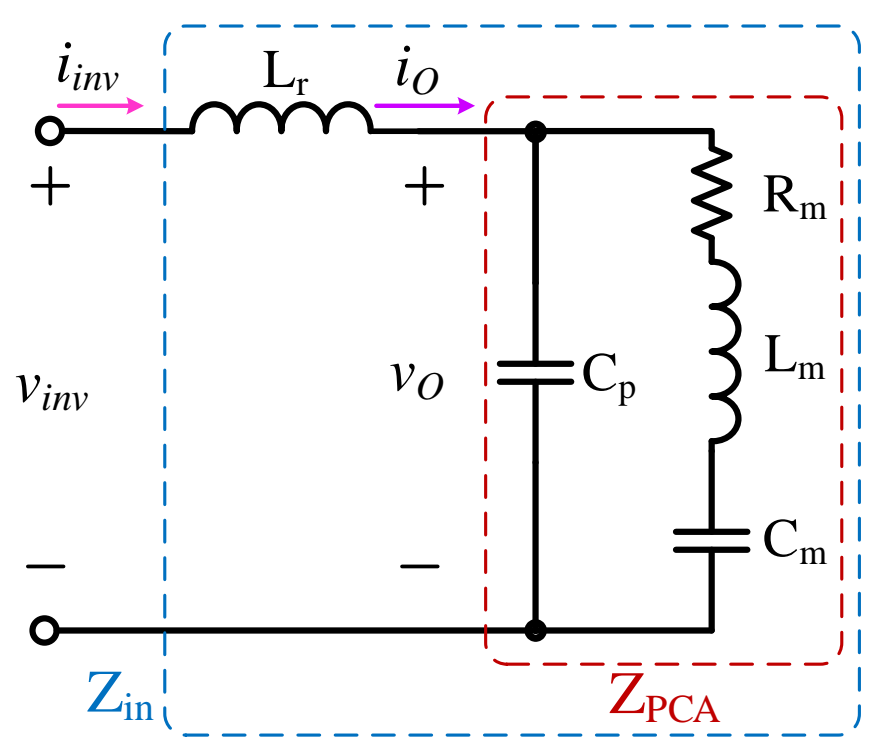

Figure 14. The equivalent circuit diagram of the resonant tank circuit combined with the piezoelectric ceramic actuator circuit model.

\subsubsection{Design of Input Low-Pass Filter}

A low-pass filter is usually added to the AC input power terminal, which is composed of an inductor $L_{\mathrm{f}}$ and a capacitor $C_{\mathrm{f}}$. The cut-off frequency $f_{\text {cut-off }}$ of the input low-pass filter is represented by

$$
f_{\text {cut-off }}=\frac{1}{2 \pi \sqrt{L_{f} C_{f}}}
$$

In order to filter high-frequency switching noise, the design consideration of the cutoff frequency $f_{\text {cut-off }}$ of the input low-pass filter is determined as one-tenth of the switching frequency $f_{\mathrm{S}}$. Rearranging (8), the design equation of the inductor $L_{\mathrm{f}}$ is given by

$$
L_{f}=\frac{1}{4 \pi^{2} f_{\text {cut-off }}^{2} C_{f}}
$$

With a cut-off frequency $f_{\text {cut-off }}$ of $4 \mathrm{kHz}$ and selecting a capacitor $C_{\mathrm{f}}$ of $470 \mathrm{nF}$, the inductor $L_{\mathrm{f}}$ is determined by

$$
L_{f}=\frac{1}{4 \pi^{2} f_{\text {cut-off }}{ }^{2} C_{f}}=\frac{1}{4 \pi^{2} \cdot(4 \mathrm{kHz})^{2} \cdot 470 n}=3.36 \mathrm{mH}
$$




\section{Experimental Results of the Proposed Drive Circuit}

In this paper, a prototype of the proposed drive circuit for supplying a $50 \mathrm{~W}$-rated piezoelectric ceramic actuator has already been implemented and testified. A photograph of the proposed prototype drive circuit for supplying a piezoelectric ceramic actuator is shown in Figure 15, and the key circuit components have been indicated in the photograph. The parameters of the utilized piezoelectric ceramic actuator are shown in Table 3. In addition, the components utilized in the prototype drive circuit for the piezoelectric ceramic actuator are shown in Table 4.

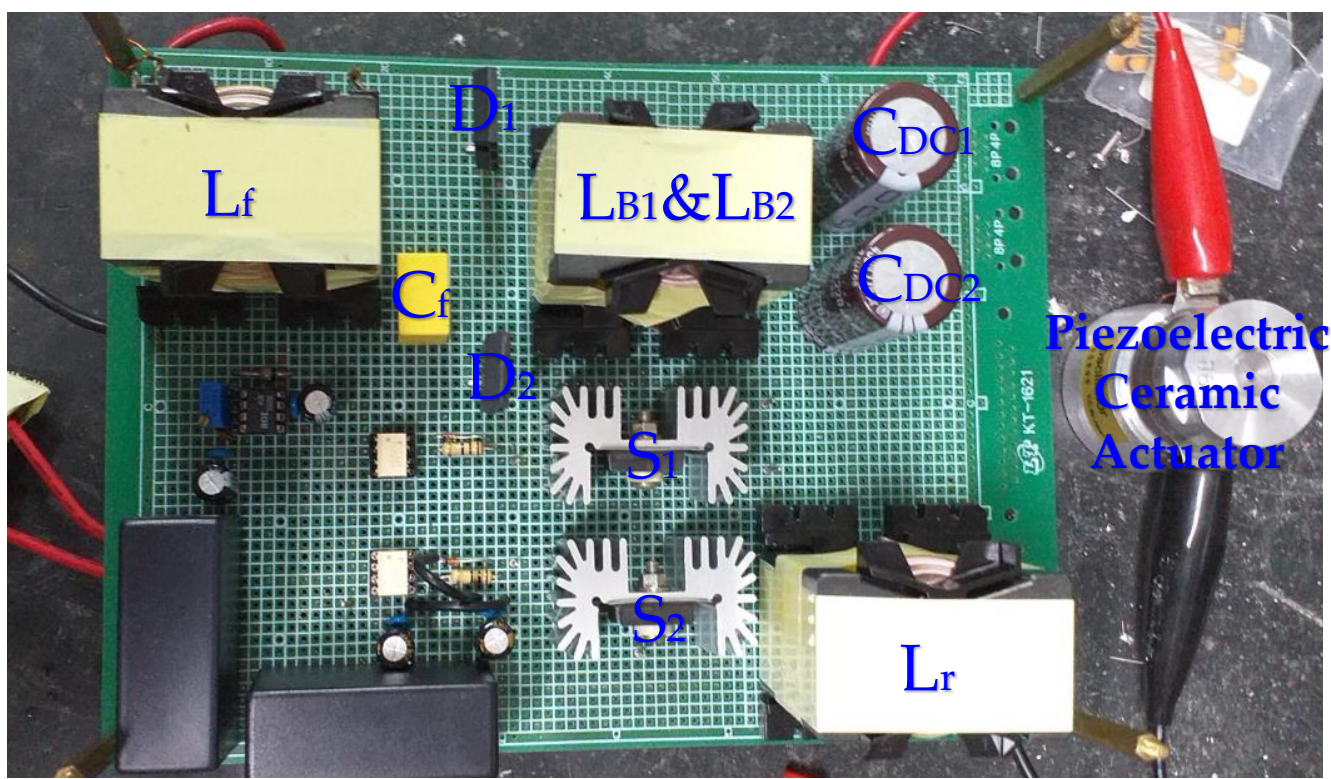

Figure 15. A photograph of the proposed prototype drive circuit for supplying a piezoelectric ceramic actuator.

Table 3. Parameters of the utilized piezoelectric ceramic actuator.

\begin{tabular}{cc}
\hline Parameter & Value \\
\hline Resonant Frequency $f_{\mathrm{r}}$ & $40 \mathrm{kHz}$ \\
Mechanical Equivalent Resistance $R_{\mathrm{m}}$ & $25 \Omega$ \\
Static Capacitance $C_{\mathrm{p}}$ & $4000 \mathrm{pF}$ \\
Rated Power $P_{\mathrm{O}}$ & $50 \mathrm{~W}$ \\
\hline
\end{tabular}

Table 4. Components utilized in the prototype of the proposed drive circuit.

\begin{tabular}{cc}
\hline Parameter/Component & Value \\
\hline Diode $D_{1}, D_{2}$ & MUR460 \\
Filter Inductor $L_{\mathrm{f}}$ & $3.36 \mathrm{mH}$ \\
Filter Capacitor $C_{\mathrm{f}}$ & $470 \mathrm{nF}$ \\
Coupled Inductor $L_{\mathrm{B} 1}, L_{\mathrm{B} 2}$ & $500 \mu \mathrm{H}$ \\
DC-linked Capacitor $C_{\mathrm{DC} 1}, C_{\mathrm{DC} 2}$ & $220 \mu \mathrm{F}$ \\
Power Switches $S_{1}, S_{2}$ & $\mathrm{~W} 12 \mathrm{NK} 90 \mathrm{Z}$ \\
Resonant Inductor $L_{\mathrm{r}}$ & $3.95 \mathrm{mH}$ \\
\hline
\end{tabular}

Figure $16 \mathrm{a}, \mathrm{b}$ presents the simulated and measured inductor current $i_{\mathrm{LB} 1}$, and it can be seen that the current $i_{\mathrm{LB} 1}$ is operated in DCM. Figure 17a,b shows the simulated and measured switch voltage $v_{\mathrm{DS} 2}$ and resonant inductor current $i_{\mathrm{Lr}}$. It can be seen that the inductor current $i_{\text {Lr }}$ lags with respect to voltage $v_{\text {DS2 }}$ so that the series resonant circuit is similar to an inductive load. Figure 18a,b presents the simulated and measured switch 
voltage $v_{\mathrm{DS} 1}$ and switch current $i_{\mathrm{DS} 1}$; thus, ZVS occurred on the power switch for lowering the switching losses. Figure $19 \mathrm{a}, \mathrm{b}$ depicts the simulated and measured output voltage $v_{\mathrm{O}}$ and output current $i_{\mathrm{O}}$. It can be seen from the waveform that the output voltage $v_{\mathrm{O}}$ lags the output current $i_{\mathrm{O}}$, so the piezoelectric ceramic actuator has capacitive characteristics.

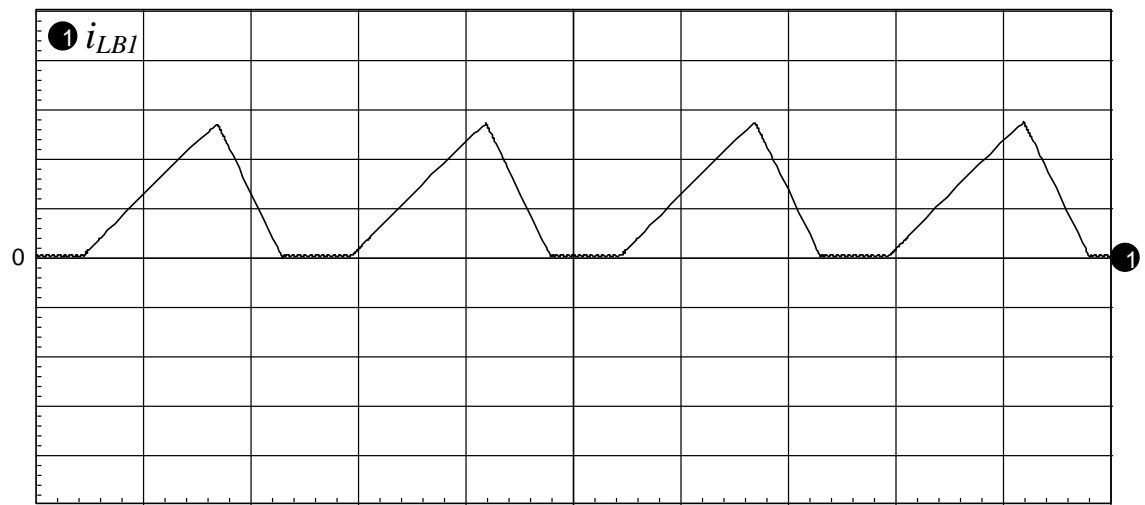

(a)

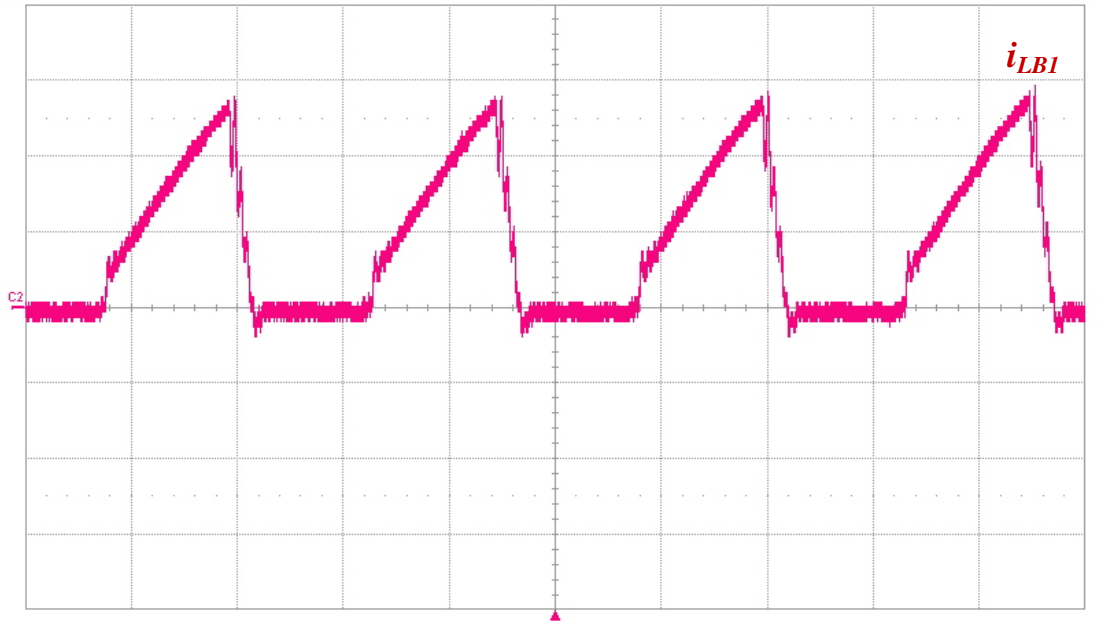

(b)

Figure 16. (a) Simulated and (b) measured inductor current $i_{\mathrm{LB} 1}(1 \mathrm{~A} / \mathrm{div})$; time scale: $10 \mu \mathrm{s} / \mathrm{div}$.

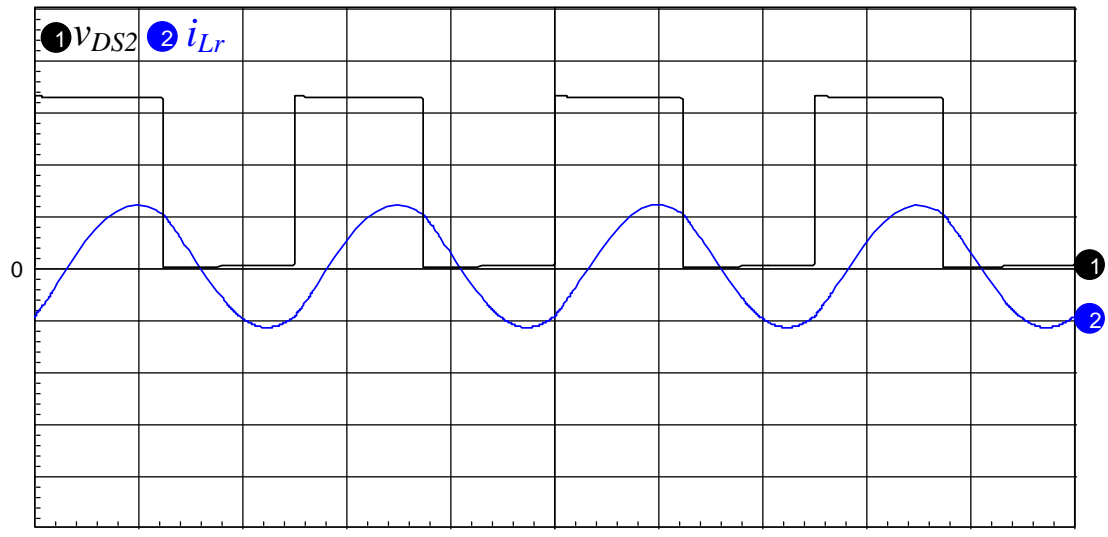

(a)

Figure 17. Cont. 


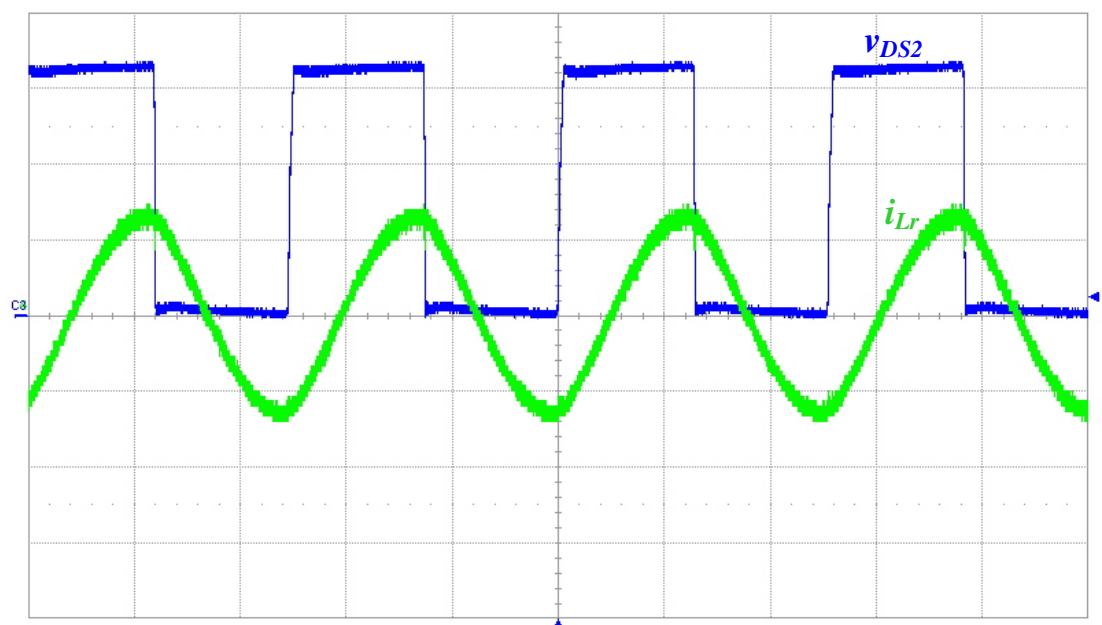

(b)

Figure 17. (a) Simulated and (b) measured switch voltage $v_{\text {DS2 }}(200 \mathrm{~V} /$ div $)$ and resonant inductor current $i_{\operatorname{Lr}}(1 \mathrm{~A} / \mathrm{div})$; time scale: $10 \mu \mathrm{s} /$ div.

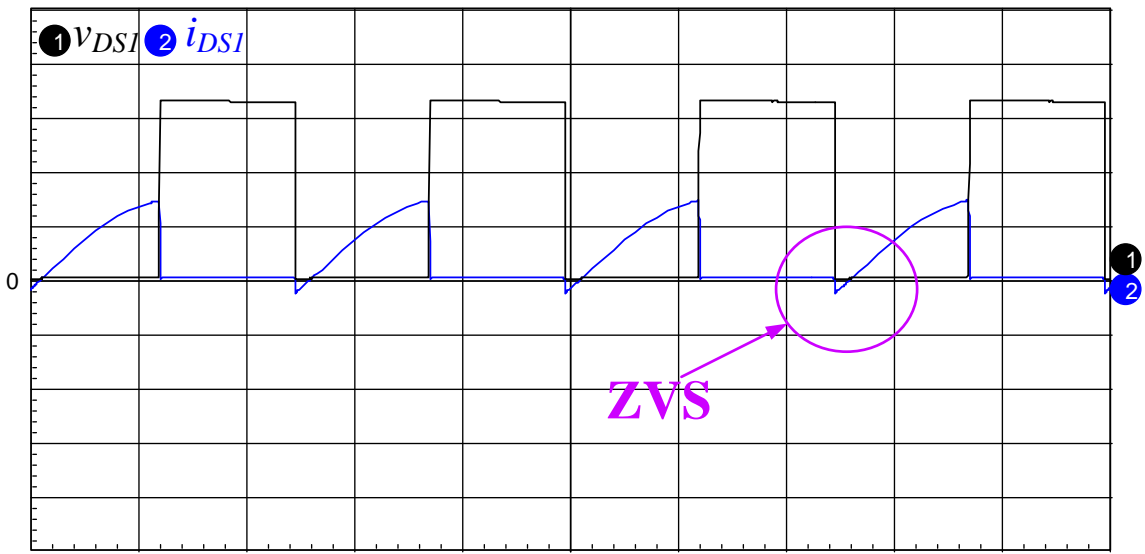

(a)

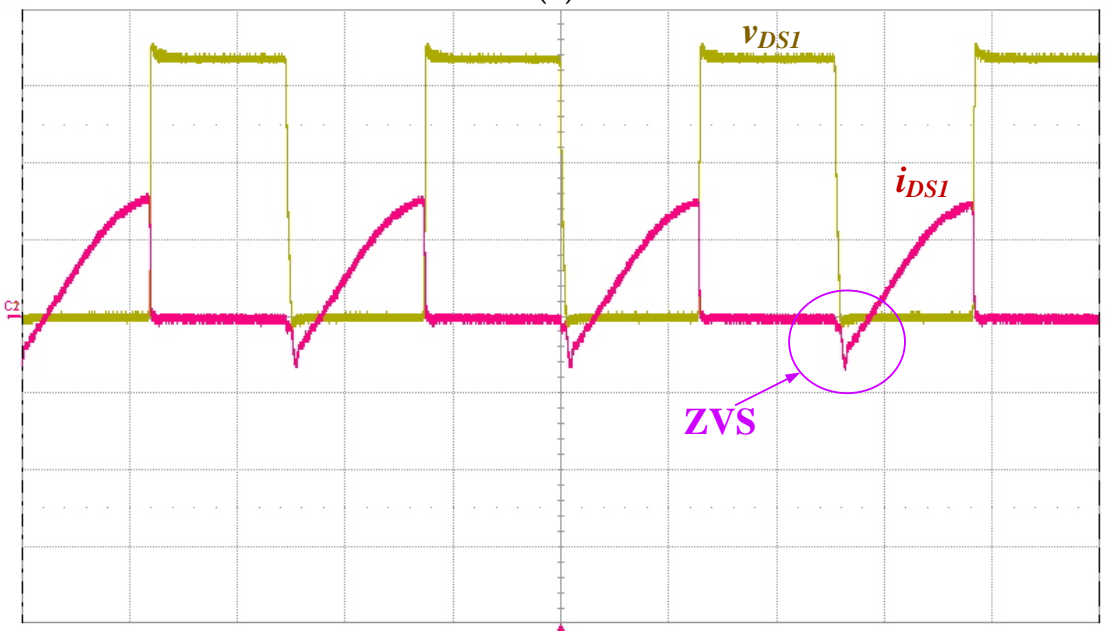

(b)

Figure 18. (a) Simulated and (b) measured switch voltage $v_{\mathrm{DS} 1}(200 \mathrm{~V} / \mathrm{div})$ and switch current $i_{\mathrm{DS} 1}$ (2 A/div); time scale: $10 \mu \mathrm{s} /$ div. 


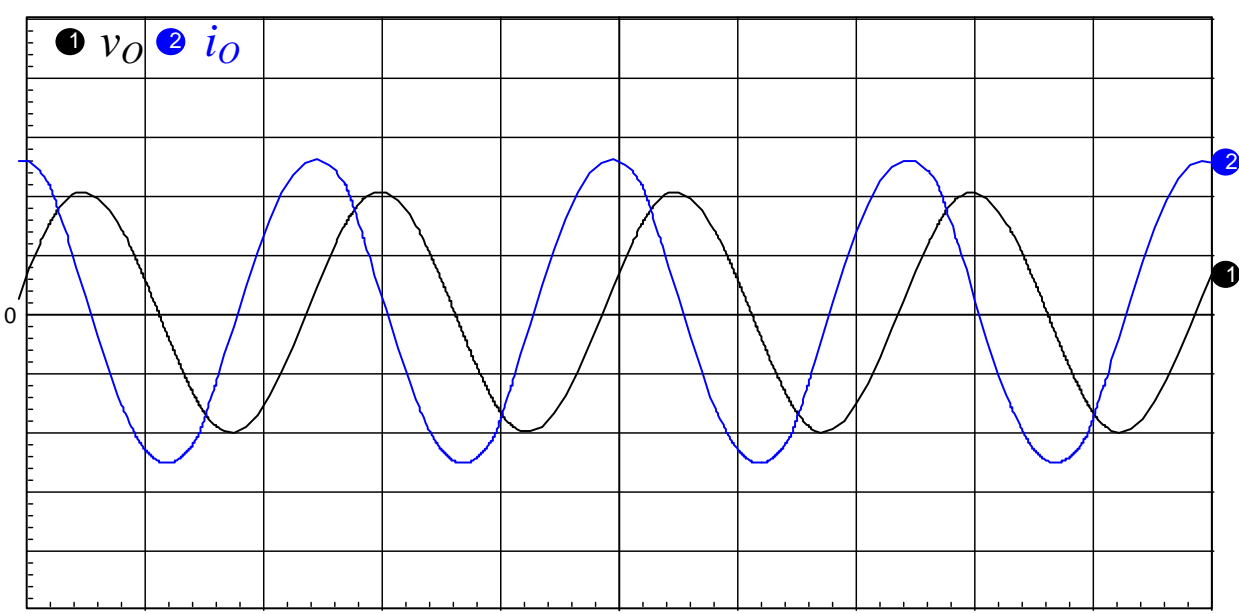

(a)

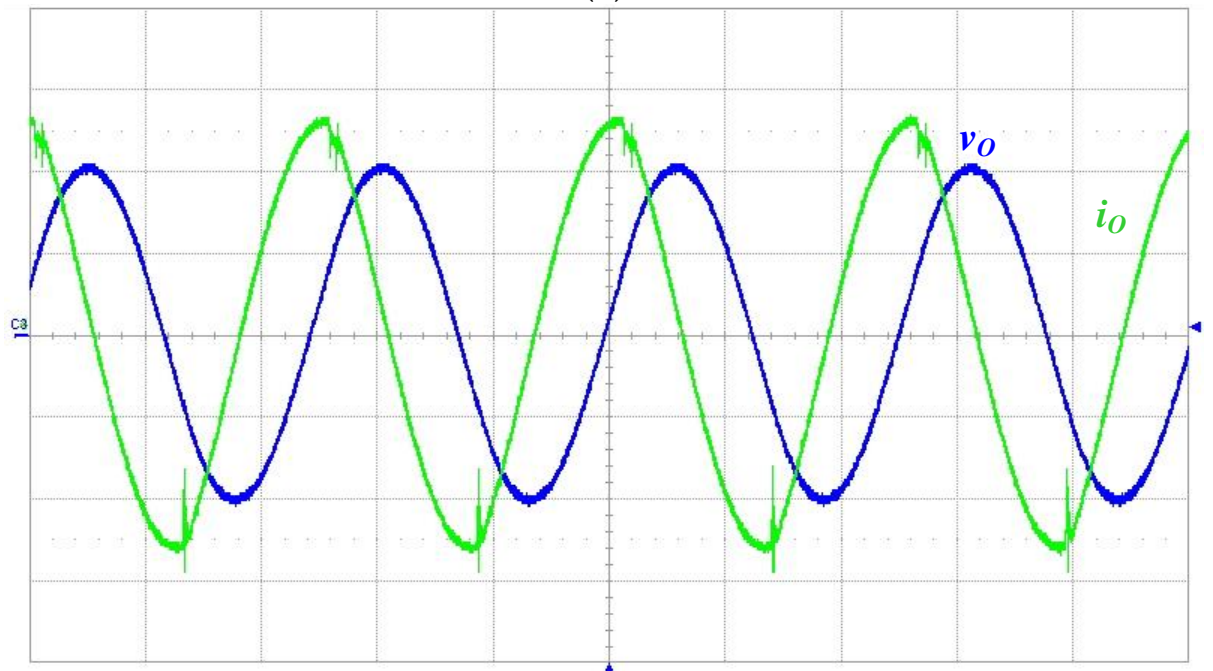

(b)

Figure 19. (a) Simulated and (b) measured output voltage $v_{\mathrm{O}}(500 \mathrm{~V} / \mathrm{div})$ and current $i_{\mathrm{O}}(0.5 \mathrm{~A} / \mathrm{div})$; time scale: $10 \mu \mathrm{s} / \mathrm{div}$.

The simulated and measured waveforms of input utility-line voltage $v_{\mathrm{AC}}$ and current $i_{\mathrm{AC}}$ are respectively shown in Figure 20a,b, and it can be seen that PFC is achieved in the proposed drive circuit. Figure 21 shows the use of a power analyzer (Tektronix PA 4000) to measure the harmonic components of the AC input current and compare it with the IEC 61000-3-2 class C standard. From the figure, it is known that all current harmonics meet the requirements. Additionally, the measured power factor and the input utility-line current total-harmonic distortion (THD) of the proposed drive circuit are 0.8683 and $3.4927 \%$, respectively. 


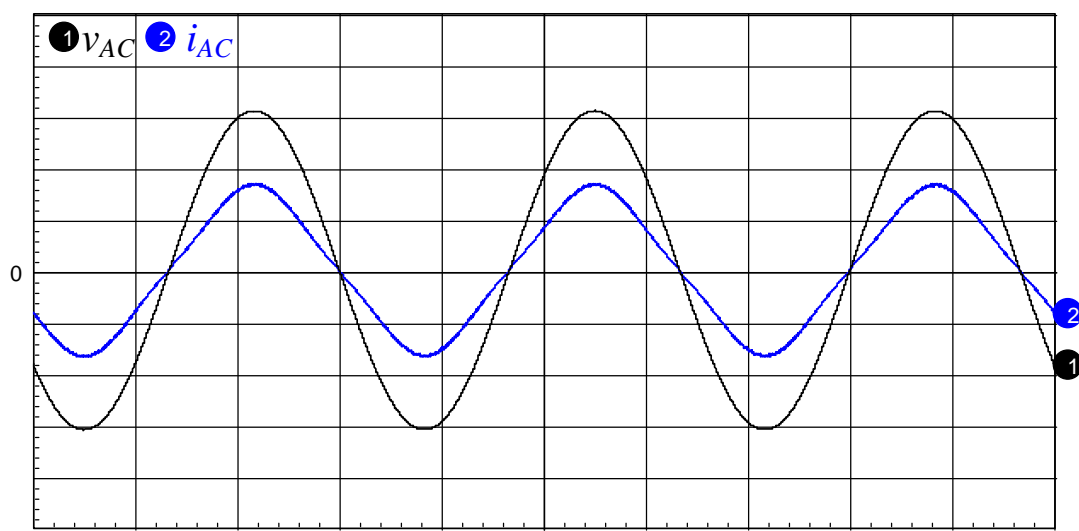

(a)

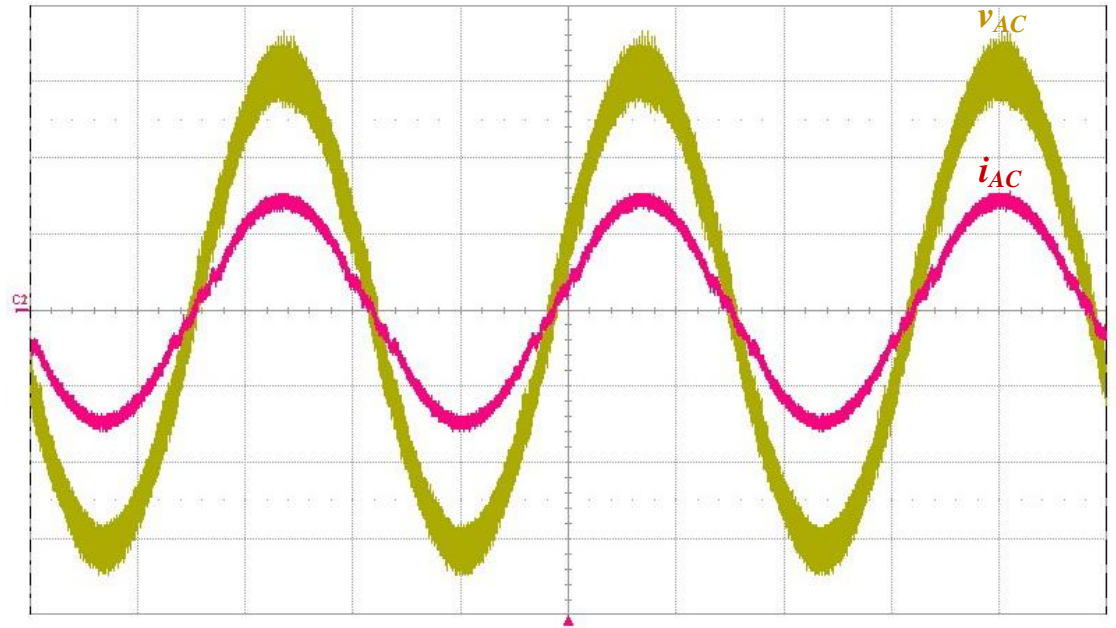

(b)

Figure 20. (a) Simulated and (b) measured input utility-line voltage $v_{\mathrm{AC}}(50 \mathrm{~V} / \mathrm{div})$ and current $i_{\mathrm{AC}}$ (1 A/div); time scale: $5 \mathrm{~ms} /$ div.

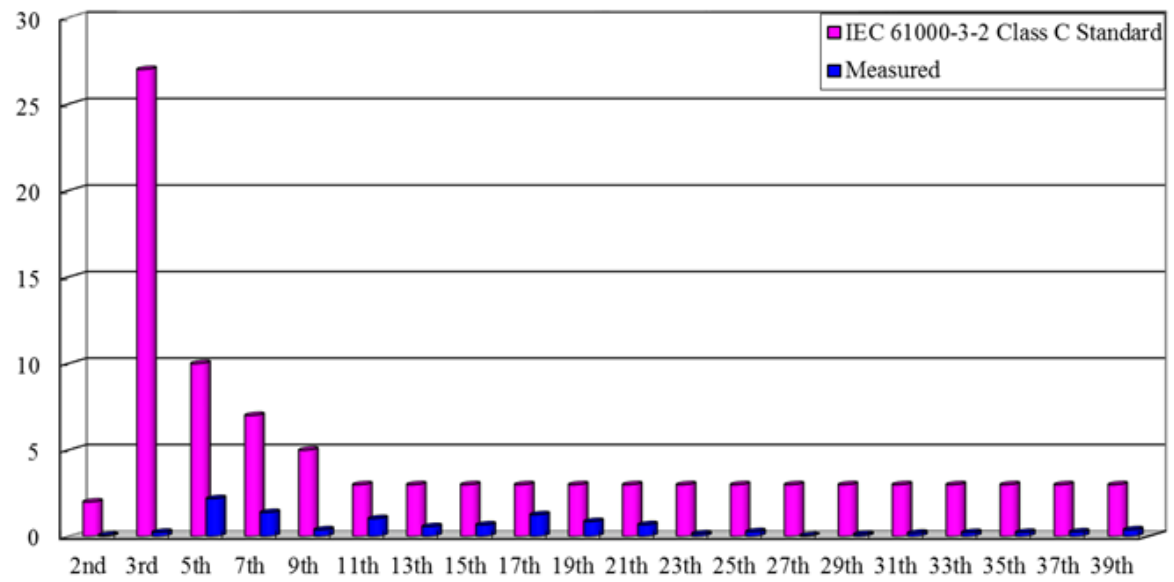

Figure 21. Measured harmonics of the input utility-line current in comparison with the IEC 61000-3-2 class $\mathrm{C}$ standard.

\section{Conclusions}

This paper proposes a novel and cost-effective drive circuit, which combines a dual boost converter with a coupled inductor and a half-bridge resonant inverter, with PFC and soft-switching features for providing a piezoelectric ceramic actuator. A $50 \mathrm{~W}$-rated 
prototype drive circuit has been implemented and tested with an input utility-line voltage of $110 \mathrm{~V}$. From the experimental results at a $110 \mathrm{~V}$ input utility-line voltage, the driving circuit developed in this thesis has as characteristics a high power factor $(>0.86)$ and a low input current total-harmonic-distortion factor $(<4 \%)$, and two power switches possess the ZVS feature.

Author Contributions: C.-A.C. and H.-L.C. conceived and designed the circuit. C.-H.C. and E.-C.C. carried out the circuit simulations and designed the circuit parameters. C.-Y.T. and L.-F.L. carried out the prototype circuit, measured experimental results, and wrote original draft preparation with guidance from C.-A.C. E.-C.C. revised the manuscript for submission. All authors have read and agreed to the published version of the manuscript.

Funding: This research was funded by the Ministry of Science and Technology (MOST) of Taiwan under its grant with reference numbers MOST 109-2221-E-214-011 and MOST 110-2221-E-214-014.

Conflicts of Interest: The authors declare no conflict of interest.

\section{References}

1. Lee, J.H.; Lee, H.C.; Choi, J.H.; Park, S.J.; Nam, H.G. 10kW Industrical Ultrasonic Welder Design. In Proceedings of the 31st International Telecommunications Energy Conference, Incheon, Korea, 18-22 October 2009; pp. 1-6.

2. Tsujino, J.; Hongoh, M.; Yoshikuni, M.; Miura, H.; Ueoka, T. Welding Characteristics and Temperature Rises of Various Frequency Ultrasonic Plastic Welding. In Proceedings of the 2005 IEEE Ultrasonics Symposium, Rotterdam, The Netherlands, 18-21 September 2005; pp. 707-712.

3. Kauczor, C.; Frohleke, N. Inverter Topologies for Ultrasonic Piezoelectric Transducers with High Mechanical Q-Factor. In Proceedings of the Annual IEEE Power Electronics Specialists Conference, Aachen, Germany, 20-25 June 2004; Volume 4, pp. 2736-2741.

4. Yu, T.; Lee, H.; Lee, D.; Song, S.; Kim, D.; Park, S. Design of LC Resonant Inverter for Ultrasonic Metal Welding System. In Proceedings of the 2008 International Conference on Smart Manufacturing Application, Goyangi, Korea, 9-11 April 2008; pp. 543-548.

5. Agbossou, K.; Dion, J.-L.; Carignan, S.; Abdelkrim, M.; Cheriti, A. Class D Amplifier for a Power Piezoelectric Load. In IEEE Transactions on Ultrasonics, Ferroelectrics, and Frequency Control; IEEE: Piscataway, NJ, USA, 2000; Volume 47, pp. 1036-1041.

6. Ma, K.H.; Chang, W.C.; Lee, Y.C. A New Tracking Method with FPGA Chip for Ultrasonic Welding System. In Proceedings of the 2009 International Conference on Power Electronics and Drive Systems, Taipei, Taiwan, 2-5 November 2009; pp. 369-370.

7. Volosencu, C. Control System for Ultrasonic Welding Devices. In Proceedings of the IEEE International Conference on Automation, Quality and Testing, Cluj-Napoca, Romania, 22-25 May 2008; Volume 2, pp. 135-140.

8. Lian, Y.; Gao, C.; Liu, X. A hybrid driving strategy for piezoelectric actuator. In Proceedings of the 2013 International Conference on Mechatronic Sciences, Electric Engineering and Computer (MEC), Shenyang, China, 20-22 December 2013; pp. 3800-3804.

9. Cheng, L.; Kang, Y.; Chen, C. A Resonance-Frequency-Tracing Method for a Current-Fed Piezoelectric Transducer. In IEEE Transactions on Industrial Electronics; IEEE: Piscataway, NJ, USA, 2014; Volume 61, pp. 6031-6040.

10. Ghasemi, N.; Zare, F.; Davari, P.; Weber, P.; Langton, C.; Ghosh, A. Power electronic converters for high power ultrasound transducers. In Proceedings of the 2012 7th IEEE Conference on Industrial Electronics and Applications (ICIEA), Singapore, 18-20 July 2012; pp. 647-652.

11. Zhou, Y.; Zhou, B.; Li, S. Driving Performance Analysis of a Novel Piezoelectric Actuator. In Proceedings of the 2010 International Conference on Measuring Technology and Mechatronics Automation, Washington, DC, USA, 13-14 March 2010 ; pp. $34-37$.

12. Lai, J.A. Two-Stage Driver for Piezoelectric Actuator. Master's Thesis, Chung Yuan Christian University, Taoyuan City, Taiwan, 2004. Available online: https:// hdl.handle.net/11296/qmkd88 (accessed on 9 October 2021).

13. Jittakort, J.; Sangswang, A.; Naetiladdanon, S.; Koompai, C.; Chudjuarjeen, S. Full Bridge Resonant Inverter Using Asymmetrical Control with Resonant-frequency Tracking for Ultrasonic Cleaning Applications. J. Power Electron. 2017, 17, 1150-1159.

14. Jittakort, J.; Sangswang, A.; Naetiladdanon, S.; Chudjuarjeen, S.; Koompai, C. LCCL Series Resonant Inverter for Ultrasonic Dispersion System with Resonant Frequency Tracking and Asymmetrical Voltage Cancellation Control. In Proceedings of the IECON 2015-41st Annual Conference of the IEEE Industrial Electronics Society, Yokohama, Japan, 9-12 November 2015.

15. Cheng, C.A.; Chang, C.H.; Cheng, H.L.; Chung, T.Y. A single-stage high-PF driver for supplying a T8-type LED lamp. In Proceedings of the International Power Electronics Conference (IPEC-Hiroshima 2014-ECCE Asia), Hiroshima, Japan, 18-21 May 2014; pp. 2523-2528. 